\title{
Better Support Services for Better Mental Health?-The Case of Depression among Parents on Welfare
}

\author{
Eliza Ahmed \\ Australian National University, Canberra, Australia \\ Email: Eliza.Ahmed@anu.edu.au
}

How to cite this paper: Ahmed, E. (2018). Better Support Services for Better Mental Health?-The Case of Depression among Parents on Welfare. Open Journal of Depression, 7, 1-16.

https://doi.org/10.4236/ojd.2018.71001

Received: June 28, 2017

Accepted: February 24, 2018

Published: February 27, 2018

Copyright $\odot 2018$ by author and Scientific Research Publishing Inc. This work is licensed under the Creative Commons Attribution International License (CC BY 4.0).

http://creativecommons.org/licenses/by/4.0/

Open Access

\begin{abstract}
The present study aims to investigate independent and interactive impacts of risk and protective factors influencing depression among parents receiving welfare. The study uses panel data from the first two waves of the nationally representative Longitudinal Study of Australian Children. The analytic sample included 1204 parents of children aged 4 - 5 years who participated in both of the waves and received government payments as their main income source in Wave 1. At Wave 2, twenty seven percent of all participant parents have income support as their main income source, and one-third of these parents reported having depressive symptoms during the 4 weeks prior to the interview. In hierarchical regression analysis, specific stressful events in the past 12 months (relationship breakdown, financial hardship, substance abuse, and death of a love one) have emerged as significant risk factors of depression. Parenting self-efficacy, timely access to support services and neighborhood belonging were found to be significant protective factors of depression. The most unique and key finding is that parents experiencing stressful events were less likely to report depression if they had adequate access to support services at times of adversity, and these results remain largely unchanged above and beyond the effects of the control variables. These findings have important implications for inculcating resilience in families on welfare in particular, through driving an institutional change that is responsive to ongoing and emergent needs. It is important that policy and health services delivery are designed in conjunction to provide maximum support for disadvantaged families at times of adversity.
\end{abstract}

\section{Keywords}

Depression, Support Services, Responsive Regulation, Disadvantaged Families, Welfare 


\section{Introduction}

There is an increasing concern that parental mental health may have far-reaching undesirable consequences for children and the wider community (Fletcher, Feeman, Garfield, \& Vimpani, 2011; Reupert, Maybery, \& Kowalenko, 2012). However, factors impeding parental resiliency to overcome mental illness have been less forthcoming in the literature. With the growing emphasis on policies and programs in this area (New South Wales Department of Community Services, 2008; Robinson, Rodgers, \& Butterworth, 2008) along with an emerging focus on responsive regulation (Ayres \& Braithwaite, 1992), this study adopts a responsive resilience framework to examine the risk and protective factors affecting depression among parents of young children who are receiving welfare.

Central to the responsive resilience approach is that governments should strengthen the resilience and responsiveness of the system to promote holistic well-being among individuals. The current study uses this concept in the mental health arena. It aims to illustrate how to improve regulatory design in responding to poorly resourced families at times of stress to meet their needs, and in turn to strengthen their capacity to act responsively.

Research investigating parental mental illness has shown its high prevalence particularly among parents of young children, ranging as high as 45 percent among those in receipt of government assistance (Edwards \& Maguire, 2012). According to the World Health Organization, depression is expected to be the largest contributor to disease burden by 2030 where the burden of depression is 50 per cent higher for females than males (World Federation for Mental Health, 2012). Another cause of concern is that the prevalence rates of mental illness among women of child-bearing age (15 to 44 years) account for the largest proportion of people suffering from depression (Australian Bureau of Statistics, 2007).

A substantial body of literature demonstrates the negative effects of parental (in most cases maternal) depression on personal activities, employment, interpersonal relationships, and quality of life (Kessler et al., 1994). Studies have shown that the presence of depressive symptoms may predict further episodes of clinical depression including substance abuse, suicide ideation, attempted suicide and death by suicide (Howarth, Johnson, Klerman, \& Weissman, 1992). Parental depression, alone or in combination with other risk factors, can also pose significant barriers to children's optimal wellbeing including school readiness, particularly for those from low income families (Reupert, Maybery, \& Kowalenko, 2012). Given that about 25 percent of children have at least one parent with mental illness (Mayberry, Reupert, Goodyear, \& Crase, 2009), it is critical that we better understand parental mental health to address it sinter generational transmission.

While this study acknowledges that depression arises from an inter play of nature and nurture, it limits its focus to social psychological factors since these are the measures taken in the Growing Up in Australia: The Longitudinal Study of Australian Children (LSAC) Survey. 


\subsection{Risk Factors and Depression}

Studies investigating the impact of risk factors on depression have predominantly focused on demographic variables. Generally, low income, single parenthood, women, lower than year 10 education, unemployment, poor physical health, and living in urban areas are the strongest risk factors that increase the likelihood of depression (Davidson \& Singelmann, 2010; The National Alliance on Mental Illness, 2009). Other researchers suggest that the above associations are not linear but rather interact in the formation of depressive symptoms. For example, prevalence for depression has been found to vary considerably based on age, gender and marital status, with single women reporting lower rates of depression with increased age whereas single men report increasing rates of depression with age (Patten, Wang, Williams, Currie, Beck et al., 2006).

More recent studies have documented that in most cases of depression, approximately 60 to 70 percent of depression is due to environmental factors and poor coping skills. Family members living with depressed adult(s) are 1.5 to 3 times more likely to develop depression than those not living with depressed adult(s) (Institute of Health Economics, 2008). Other studies have focused on traits such as neuroticism, negative emotionality, heightened interpersonal dependency, self-criticism and perfectionism suggesting that people who regard the causes of negative events as global, stable and internal due to the self are more likely to develop depression (Beck, 1967; Klein, Kotov, \& Bufferd, 2011).

One of the contextual risk factors consistently linked to depression is the exposure to stressful life events (Gibb, Butler, \& Beck, 2003; Hammen, Kim, Eberhart, \& Brennan, 2009). Studies exploring the effect of stressful events have shown that, whether expected or unexpected, they can influence mental health of one or more family members (Department of Health and Aged Care, 2000). People can encounter stressful events over multiple life domains such as personal (i.e. own illness, substance abuse), family (i.e. death of a loved one, domestic violence), interpersonal (i.e. loss of a romantic relationship) and work (i.e. job loss, troubles with coworkers). As relationships between these domains are interconnected (i.e. the personal domain can interfere with work, the work domain can interfere with family), researchers have attempted to examine their separate effects on adult mental health (Baxter, Qu, Weston, Moloney, \& Hayes, 2012).

The relationship between stressful events and depression is not always clear-cut. It is different for different populations. This study examines the form that such relationships take among one of the most vulnerable social groups, parents receiving welfare.

\subsection{Protective Factors and Depression}

Just as adverse life events are risk factors for depression, there are protective factors that ameliorate against the harm they pose to an individual's mental health. Since the introduction of the concept of self-efficacy by Bandura (1977), an extensive body of research has consistently found that those with high per- 
ceived self-efficacy show substantially fewer symptoms of depression than those with low self-efficacy (i.e. Leahy-Warren, McCarthy, \& Corcoran, 2012). These studies have explained that high self-efficacy among parents promotes a sense of calmness/serenity in approaching difficult tasks and activities whereas parents with low self-efficacy are likely to focus on negatives in their lives, blaming external factors that can foster anxiety, stress, and/or depression.

Other protective factors that have been found critical in contributing to adult mental health are support systems and neighborhood belonging (see De Silva, McKenzie, Harpham, \& Huttly, 2005 for a review). Past research has emphasized the importance of relationships among individuals, groups and organizations in building different systems in communities to reduce risks of mental illness. Several studies have provided evidence that a strong sense of community is associated with positive mental health outcomes (Greenfield \& Marks, 2010). The argument posed is that individuals living in a cohesive community are psychologically and socially better equipped with skills and networks which help them fight stressors and depression than those living in a less cohesive community. Past studies have demonstrated that cohesive communities are more successful at relating to each other to produce sustainable local support services (Edwards \& Maguire, 2011; Kawachi \& Berkman, 2000; Sampson, Raudenbush, \& Earls, 1997) which are likely to influence social and emotional outcomes.

\subsection{The Present Study}

This paper asks what is needed at the individual, institutional and community levels to build resilience against depression among parents on welfare. The following three specific hypotheses test the independent and interactive effects of the risk and protective factors on depression:

- Parents experiencing stressful events are more likely to report depression (Hypothesis 1).

- Parents who score high on parenting self-efficacy (individual level), access to support services (institutional level) and neighborhood belonging (community level) are less likely to report depression (Hypothesis 2).

- The protective factors are expected to moderate the relationships between risk factors and depression (Hypothesis 3). For example, parenting self-efficacy would buffer the negative effects of stressful events on depression (Hypothesis 3a). Similarly, timely access to support services and neighborhood belonging would buffer the negative effects of stressful events on depression (Hypothesis $3 b$ and $3 c$, respectively).

To the best of the author's knowledge, no published study to date has examined independent and interactive effects of these risk and protective factors among parents with young children who are receiving welfare, one of the most vulnerable populations in Australia. Despite the fact that the concepts of stressful events, parenting self-efficacy and neighborhood connectedness have received a great deal of attention in the literature, they have not been widely inves- 
tigated for the population specified in this study Parents with young children receiving welfare are buffeted by a range of government policies: return to work policies, child care policies, school policies, child protection policies, and health policies. Their capacity to comply with these policies is likely to be seriously compromised if they are battling depression. Managing depression in this population not only benefits families, but also may be the leverage point for building more effective working relationships with parents of young children in other areas of government policy.

\section{Methodology}

\subsection{Data, Sample and Procedure}

This study utilized two waves (Wave 1 in 2004 and Wave 2 in 2006) of panel data from the Kindergarten cohort (K-cohort) of the LSAC ${ }^{1}$. The analytic sample in this study comprised 1204 parents who participated in both waves and received income support payment as their main income source government payments in Wave 1. Parents were asked if income support (Parenting Payment Partnered, Parenting Payment Single, New Start Allowance) was their main source of income. Twenty seven percent of all participant parents have income support as their main income source.

At both Waves 1 and 2, trained researchers administered a face-to-face interview in the child's home with the parents (known as the "primary caregiver"). Self-report information was collected using questionnaires from parents of children aged $4-5$ years at the time of Wave 1 interview. These parents were followed up and interviewed again at Wave 2 in $2006^{2}$.

\subsection{Measures}

All demographic variables (Household composition, age, education, employment, health condition, Socio-Economic Indexes for Areas (SEIFA) ${ }^{3}$, main language at home, and prior depression) were used from Wave 1 whereas other variables including the dependent variable (depression) were taken from Wave 2. The selection of these variables was based on past studies which demonstrated their association with depression among adults (i.e. Gallo, Bradley, Siegel, \& Kasl, 2000). Because depression is likely to be higher among those with a prior history of depression (Eaton, Martins, Nestadt, Bienvenu et al., 2008), depression at Wave 1 was included as a control variable. Gender of parents was not used as a

${ }^{1}$ The LSAC is conducted in partnership between the Department of Social Services (DSS), the Australian Institute of Family Studies (AIFS) and the Australian Bureau of Statistics (ABS). The ethical approval of LSAC research protocol was obtained from the AIFS Ethics Committee. The findings and views reported in this paper are those of the author and should not be attributed to DSS, AIFS or the ABS. For further information, visit:

http://www.fahcsia.gov.au/our-responsibilities/families-and-children/programs-services/growing-up -in-australia-the-longitudinal-study-of-australian-children-lsac.

${ }^{2}$ The attrition rate between Waves 1 and 2 was $10 \%$. This is a lower attrition rate than for most other comparable overseas studies (Gray \& Smart, 2008).

${ }^{3}$ http://www.abs.gov.au/websitedbs/censushome.nsf/home/seifa. 
control variable as 97 percent of all parents in Wave 1 were mothers.

Specific stressful events (relationship breakdown, work stress, major financial crisis, substance abuse, and death of a love one) are considered as risk factors whereas access to support services, parental self-efficacy, and neighborhood belonging are considered as protective factors of depression.

Depression is the dependent variable in this study, which was assessed by using the standard Kessler Psychological Distress Scale (K6) ${ }^{4}$.

Details of all these measures are described below:

Dependent Variable

Depression is the dependent variable in this study that was assessed by using the standard Kessler Psychological Distress Scale (K6) ${ }^{5}$. All parents were asked to rate how they have been feeling over the past 30 days: 1) so sad nothing could cheer you up; 2) nervous; 3) restless or fidgety; 4) hopeless; 5) everything was an effort; 6) worthless? Responses were scored from 0 to 4 ("none", "a little", "some", "most", or "all the time") with a maximum score of 24. For the purposes of regression analysis, depression was used as a continuous measure by averaging six items $(\mathrm{M}=1.68, \mathrm{SD}=.70)$.

Demographic Factors

Age of parents at wave 1 was used as a continuous variable $(\mathrm{M}=33.47, \mathrm{SD}=$ 6.31 ). To understand the distribution, age was categorized as $\leq 30$ years (22 percent), 31 - 35 years (35 percent), 36 - 40 years (29 percent), and 41 years and above (14 percent).

Family structure indicates whether the participant parent is from one-parent families with children or from two parent families with children. Two-parent families are defined as those where the parent lives together with a partner who may or may not be the biological parent of the study child. One-parent families are those in which the study child lives with one female parent only (who is not necessarily the child's biological mother).

Data on Family structure was scored as a dummy variable for use in the regression analysis ( $1=$ one-parent families (40\%), $0=$ two-parent families (60\%)).

Education of parents was coded as a dummy variable $(1=$ post Year 10 or equivalent, $0=$ up to Year 10 or equivalent). Sixty percent of parents completed Year 10 or equivalent level of education.

Employment status of parents was measured by asking: Last week, did you do any work at all in a job, business or farm? $(1=$ Yes, $0=$ No). About two-thirds of all parents (61 percent) reported as not doing any work in a job, business or farm.

Health condition was measured by asking if the parent has any medical conditions or disabilities that have lasted, or are likely to last, for six months or more $(1=$ yes, $0=$ no). Thirty three percent of the parents reported having a health

${ }^{4}$ The K6 scale is a widely used indicator for the likelihood of serious mental illness (Kessler et al., 2003). The K6 has been shown to have good internal consistency and concordance with other, longer measures of depression and anxiety disorders (Kessler et al., 2010).

${ }^{5}$ The K6 scale is a widely used indicator for the likelihood of serious mental illness (Kessler et al., 2003). The K6 has been shown to have good internal consistency and concordance with other, longer measures of depression and anxiety disorders (Kessler et al., 2010). 
condition that includes both physical and psychological concerns (moderately correlated with depression, $\mathrm{r}=.12, p<.001)$.

Main language spoken at home was identified by asking parents whether the child mainly spoke a language other than English at home. Languages were classified according to the Australian Standard Classification of Languages (ABS, 2005), and grouped as $1=$ English as the main language, $0=$ other than English for current analysis. Eighty seven percent of the children had English as their main language at home.

Socio-Economic Indexes for Areas (SEIFA) was assessed using the Socio Economic Index for Areas (SEIFA) measure of Relative Socio-Economic Disadvantage (IRSD). IRSD scores were grouped using its mean and a dummy variable was created $(0=$ disadvantaged and highly disadvantaged, $1=$ advantaged and highly advantaged). Thirty two percent of parents are living in areas of disadvantage and high disadvantage.

Prior depression measure has exactly the same items as the dependent variable (Depression) but measured in Wave $1(\mathrm{M}=1.84, \mathrm{SD}=.73)$.

Risk and Protective Factors

Stressful life events: The LSAC Wave 2 has focused on 17 stressful life events that were measured by responses (yes $=1$, no $=0$ ) to the events that occurred primarily to the parent in the year prior to the interview. Parents were asked: In the last year, have any of the following happened to you (or your partner)? The events covered are pregnancy/new arrival, serious illness or injury, death, relationship breakdown, financial crisis, job loss, substance abuse, legal problems, having been robbed, and serious difficulties at work including unemployment.

To reduce the number of events in the regression analysis, chi-square tests were run to identify what events are significantly more prevalent among parents on welfare compared to parents not on welfare. Five events appeared as significant: relationship breakdown $\left(\chi^{2}=25.44, p<.001\right)$, job related stress $\left(\chi^{2}=11.93\right.$, $p<.05)$, substance abuse $\left(\chi^{2}=28.07, p<.001\right)$, major financial stress $\left(\chi^{2}=45.15\right.$, $p<.001)$, and death of a loved one $\left(\chi^{2}=8.64, p<.01\right)$.

Parenting Self-efficacy (Individual-level of protective factor): To assess parenting self-efficacy, parents were asked 4 questions: How often 1) does this child behave in a manner different from the way you want him/her to? (reverse scored); 2) do you think that this child's behaviour is more than you can handle? (reverse scored); 3) do you feel that you are good at getting this child to do what you want him/her to do? and 4) do you feel that you are in control and on top of things when you are caring for this child? Responses on these items were collected on a 5-point scale, ranging from $1=$ "never/almost never" to $5=$ "always/almost always". All four items were aggregated to use in the regression analysis $(\mathrm{M}=4.04 ; \mathrm{SD}=.70)$.

Access to support services (Institutional-level of protective factor): To measure whether parents could access the required support services at the time of crisis, parents were asked: In the last 12 months, have there been any of the services listed that anyone in this family has needed but could not get? The listed services 
are counselling, adult mental health, drug or alcohol, disability, housing, parent support groups, migrant/charities/religious groups, and parenting programs. A reverse index (yes $=1$, no $=0$ ) was created from responses indicating that 6 percent of the parents needed a specific service at the time of crisis but could not get access to it.

Neighborhood belonging (Community-level of protective factor): To assess perceived neighborhood belonging, parents were asked 4 questions: How strongly do you agree or disagree that: 1) If you need information about local services, you know where to find that information; 2) You are well informed about local affairs; 3) You feel a strong sense of identity with your neighborhood; and 4) Most people in your neighborhood can be trusted. Responses on these items were collected on a 5 -point scale, ranging from $1=$ "strongly agree" to $5=$ "strongly disagree". All four items were aggregated to use in the regression analysis $(\mathrm{M}=2.36$; $\mathrm{SD}=.63)$.

\subsection{Data Analysis Overview}

Descriptive findings are presented first, followed by hierarchical regression analysis examining the independent and interactive effects of the risk and protective factors on depression.

The hypotheses were tested using the following order: demographic factors were introduced on Step 1 of the hierarchical model; the risk and protective factors were entered on Step 2; and the interaction terms on Step 3.

\section{Results}

\section{1) Descriptive analysis}

Demographic factors: The mean age of parents was $33.47(\mathrm{SD}=6.31)$, with a range of 18 - 51 years. While 60 percent of all parents completed Year 10 education, the rate of employment participation was low (39 percent). Most respondents were partnered (60 percent) and one-third reported having a health condition. Eighty seven percent of the parents reported that their children's main language at home was English. The SEIFA index of advantage/disadvantage shows that 32 percent of the families were living in disadvantaged areas.

Risk and protective factors: The death of a close family friend or another relative was the most commonly experienced stressful event, with one quarter of the parents reporting that this had occurred to them or to their partner in the previous 12 months. The next most commonly experienced stressful event was financial stress (14 percent), followed by stress related to a work related matter (6.70 percent), relationship (5.90 percent) and substance abuse (5 percent).

Over the 12-month period, 67 percent of parents indicated that at least one stressful event had occurred to either them or their partner. Of the 67 percent parents, 27 percent had experienced one of the five events and 21 percent had encountered two of the five events in the last 12 months.

This study examined impact of three protective factors: parenting self-efficacy, 
access to support services and neighborhood belonging. As found, six percent of parents reported experiencing difficulties in accessing support services at times of need. The mean scores of perceived parenting self-efficacy and neighborhood belonging were 4.04 and 2.36, respectively, indicating more positive perceptions.

Depression: The mean score of depression ${ }^{6}$ among parents on welfare over a four-week period was 1.68. This appeared significantly higher $(\mathrm{t}=4.34, p<.001)$ when compared with depression among parents not on welfare $(M=1.48)$.

In order to estimate depression persistence over two years (2004 and 2006), a binary variable depressed/not depressed was computed. Parents who reported depression over a four-week period at both waves (2004 and 2006) were defined as the persistent depression sample. The persistence of depression between 2004 and 2006 was significantly higher for parents on welfare (58 percent) than what found for parents not on welfare (49 percent) $\left(\chi^{2}=6.97, p<.01\right)$.

2) Hierarchical Ordinary Least Square (OLS) Regression Analysis .

In Step 1, eight socio-demographic variables were entered. As can be seen from Table 1, parental age, health condition, and prior depressive episodes significantly contributed to increase later depression, and accounted for 29 percent of the variance.

In Step 2, risk and protective factors were entered which added an extra 8 percent variance supporting both Hypothesis 1 and Hypothesis 2 (Table 1).

Four out of the five stressful events (relationship breakdown, $\beta=.11, p<.01$; a major financial crisis, $\beta=.08, p<.05$; substance abuse $(\beta=.10, p<.01$; and death of a love one $(\beta=.07, p<.05)$ significantly and positively predicted depression.

All protective factors made strong unique contributions in predicting depression. Those who were able to access services at times of adversity were less vulnerable to symptoms of depression $(\beta=-.11, p<.001)$. Also, high levels of parenting self-efficacy $(\beta=-.11, p<.001)$ and neighborhood belonging $(\beta=-.14$, $p<.001)$ predicted less symptoms of depression.

Interaction between risk and protective factors ${ }^{8}$.

Instead of adding five separate interaction terms for five events, a new variable was formed indicating if parents experienced any one of these five events in the past 12 months. Then three interaction terms were created: "any one event $\mathrm{X}$ parenting self-efficacy", "any one event X service accessibility", and "any one event X neighborhood belonging".

In Step 3, two terms appeared significant: "any event X parenting self-efficacy" and "any event X service accessibility" (Table 1). The effect of the latter term

${ }^{6}$ The term depression is used as a continuous variable to capture individual differences in depressive symptoms rather than a clinical category such as presence or absence of a major depressive disorder. Taxometric analyses suggest that depression is best conceptualized as a continuous construct (Hankin, Fraley, Lahey, \& Waldman, 2005).

${ }^{7}$ The bi-variate correlation results, available upon request, between the outcome variable (depression) and all predictor variables in the regression analysis are also of note in so far as they appear as expected.

${ }^{8}$ Computation of interaction terms: Following Aiken and West's (1991) recommendations for regression analyses testing for interactions, two-way interaction terms were created by multiplying centered scores (the actual score minus the mean score) of predictors. 
Table 1. Standardized beta coefficients from OLS/hierarchical regression analysis in predicting depression among parents on welfare. Sample size (listwise deletion) $=699$.

\begin{tabular}{|c|c|c|c|}
\hline Variables & $\begin{array}{l}\text { Socio-demographic } \\
\text { factors }\end{array}$ & $\begin{array}{l}\text { Risk and protective } \\
\text { factors }\end{array}$ & Interaction terms \\
\hline \multicolumn{4}{|c|}{ Step 1: Demographic (Control) factors } \\
\hline Age & $.07^{\star}$ & $.10^{* *}$ & $.10^{* *}$ \\
\hline Family structure & .05 & .03 & .03 \\
\hline Education & .01 & .01 & .01 \\
\hline Employment & .04 & .04 & .04 \\
\hline Health condition & $.08^{\star *}$ & .06 & $.07^{*}$ \\
\hline Main language at home & .04 & .05 & .05 \\
\hline SEIFA & .01 & .03 & .03 \\
\hline Prior depression & $.51^{\star * *}$ & $.42^{* * *}$ & $.41^{* * *}$ \\
\hline \multicolumn{4}{|c|}{ Step 2: Risk factors (stressful life events) } \\
\hline Relationship breakdown & - & $.11^{\star *}$ & $.11^{\star *}$ \\
\hline Work stress & - & .01 & .01 \\
\hline Major financial crisis & - & $.08^{*}$ & $.07^{*}$ \\
\hline Substance abuse & - & $.10^{* *}$ & $.09^{* *}$ \\
\hline Death of a loved one & - & $.07^{*}$ & $.07^{*}$ \\
\hline \multicolumn{4}{|c|}{ Protective factors } \\
\hline Parenting self-efficacy & - & $-.11^{\star \star \star}$ & $-.16^{\star * *}$ \\
\hline Access (timely) to services & - & $-.11^{\star * *}$ & $-.18^{\star * *}$ \\
\hline Neighborhood belonging & - & $-.14^{\star * \star}$ & $-.16^{\star * *}$ \\
\hline \multicolumn{4}{|c|}{ Step 3: Moderating factors } \\
\hline $\begin{array}{c}\text { Any event }{ }^{*} \text { Parenting } \\
\text { self-efficacy }\end{array}$ & - & - & $.09^{*}$ \\
\hline $\begin{array}{c}\text { Any event }{ }^{*} \text { Access (timely) to } \\
\text { services }\end{array}$ & - & - & $.09^{*}$ \\
\hline $\begin{array}{c}\text { Any event }{ }^{*} \text { Neighborhood } \\
\text { belonging }\end{array}$ & - & - & .07 \\
\hline Adj R square & .29 & .367 & .384 \\
\hline F value & $37.09^{* * *}$ & $26.30^{\star * *}$ & $22.99^{\star * *}$ \\
\hline
\end{tabular}

${ }^{\star} p<.05,{ }^{* *} p<.01,{ }^{* * *} p<.001$.

became more pronounced in the simple slope analyses clarifying the interaction (Aiken \& West, 1991) supporting Hypothesis 3b. As Figure 1 suggests, timely access to support services can compensate for the deleterious effect of stressful events on depression $(\beta=-.09, p<.01)$ whereas a lack of timely access accelerates the adverse effects of stressful events on depression $(\beta=.07, p<.03)^{9}$.

${ }^{9}$ While these results provide some indications for potential three-way interactions among "any event", "parenting self-efficacy", "service accessibility", and "neighborhood belonging", the small sample size in the "Yes" category of the Service Accessibility variable appear to be a risk factor of the fit of the model to the data during the period of further breakdown. 


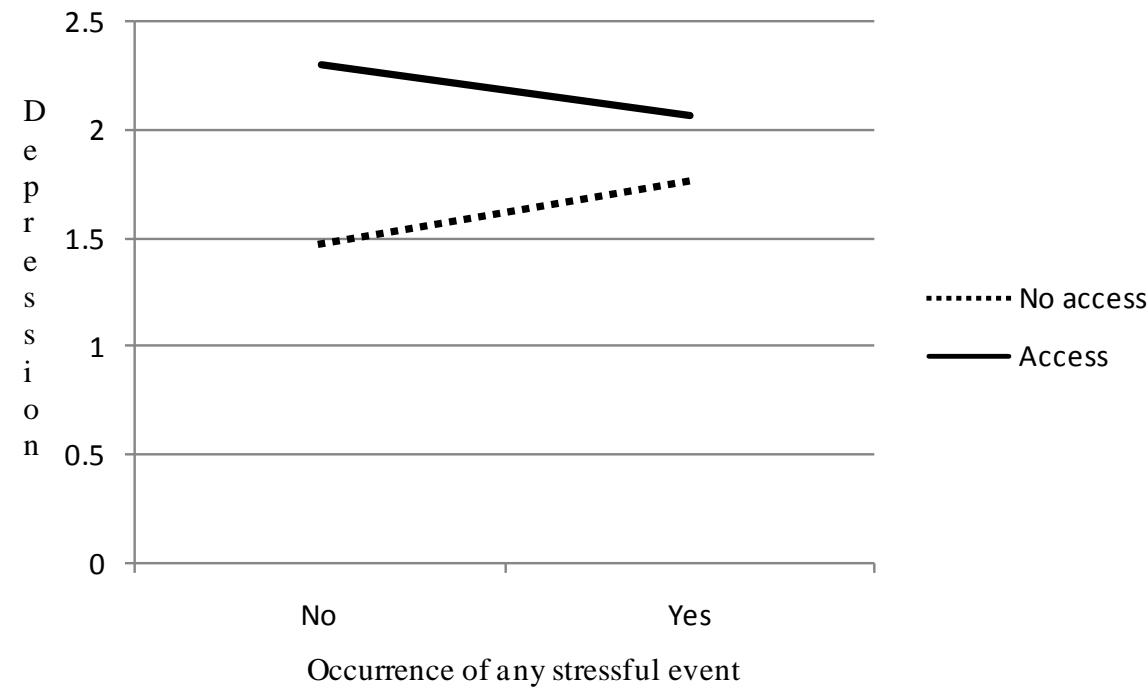

Figure 1. The role of timely access to support services in moderating the relationship between depression and stressful life event among parents on welfare. (Solid line $=p$ $<.01$; dotted line $=p<.03$.)

\section{Discussion}

Findings from the regression analysis have provided strong evidence that being exposed to stressful life events is significantly related to high levels of depression. Since occurrences of some stressful events can be beyond our control, this study also tested roles of protective factors in predicting depression at three levels: self-efficacy at an individual-level, timely access to support services at an institutional-level, and neighborhood belonging at a community-level. Findings have confirmed that all three factors play significant protective roles in lowering depression. The most important and unique result is that service accessibility buffers the deleterious effects of stressful events on depression, and this pattern of results holds true even after adjusting for all demographic variables.

These findings are of substantial clinical and public health importance in so far as they show the crucial role of the Australian service delivery system in meeting the needs of families from a disadvantaged background. The finding that service accessibility has a significant buffering role in reducing depression points to the importance of addressing regulatory measures to strengthen service accessibility by vulnerable families at crisis. To ensure that effective support services are available to vulnerable families, we need deeper insights into how these families understand the services, potential gaps in the services, including mapping their experiences of the services and how these services are meeting their needs. The studied population (parents on welfare) can be economically under-privileged, often experiencing new and ongoing daily demands which add layers of complexity and distress in their lives. What is not well known is their real/perceived barriers to access (not barriers to seek access), and such lack of information may oversimplify the efficiency of service design and delivery processes. In-depth views and expectations about support services of these families need to be re- 
flected in policy design to ensure targeted service delivery to these families at times of crisis. It is only when the integration at policy and service levels takes place that more adequate and intensive support can be offered to vulnerable families in ways that are effective for them.

Results of this study suggest that about six percent of the families could not simply access the services they sought at the time of crisis. While the LSAC data are limited in uncovering why the families could not access the services, past literature may provide some insights about what regulatory measures can be useful in providing effective access to support services for vulnerable families (Robinson, Scott, Meredith, Nair, \& Higgins, 2012). The most critical and frequently cited measure of effective access is availability via flexible entry to services for those who have already been diagnosed with a mental illness. Vulnerable families, particularly those with more complex needs, often require services from multiple systems such as general practitioners, adult counseling, parent support groups, drug/alcohol support services, and housing. Ideally, the various support services should be linked to form a holistic "wraparound" model of service delivery so families can have easy and timely access to a full array of services. To better respond to the needs of vulnerable families, the services need to build flexibility into their regulatory strategies to allow soft entry points including self-referral, after hours appointments, outreach sessions, affordability via reduced or waived fees, and meeting a minimum standard of quality. Services that are forced to operate "by the book" without any modifications to address complex circumstances often confuse doing the right things with doing things right, and are unable to strengthen the effectiveness of their deliveries.

While securing a timely appointment with a targeted service is the first step toward service accessibility, within-family factors also remain critical to prevent vulnerable families from getting the support required. These can include limited income, lack of convenient transport, personal preferences in services, stigma, and day-to-day stress including health concerns, caring responsibilities, and lack of motivation. While there is no quick fix to overcoming these barriers, it is necessary to identify, analyze and understand them to provide a targeted service delivery at times of crisis. To gain additional insights into why 6 percent of the parents could not access support services at times of crisis, follow-up in-depth interviews using the LSAC can be organized.

Prior experiences in actual receipt of services can also be critical in selecting a service. Therefore, patterns of service utilization and perceptions of services should also be analyzed when addressing the unmet mental health needs particularly for those who had accessed (or attempted to access) services earlier. Real and/or perceived barriers such as limited access to specialist supports, poor coordination between the services required, and lack of professionalism can represent a further barrier to accessing services not only for those with earlier experiences but also for those wanting access for the first time. As part of the effort to reduce real/perceived barriers, information campaigns can be advocated for service providers and the targeted families, which may enhance trusting rela- 
tionships, and the acknowledgment of the benefits of early engagement with the services.

While the above measures are crucial for improving institutional resiliency, it is also worthy to address individual and community resiliencies to combat depression. The current analyses demonstrate that both parenting self-efficacy and a sense of belonging to one's neighborhood play significant roles in reducing depression. Therefore, programs that foster parenting self-efficacy so that parents feel confident in managing stress would be beneficial to reduce the risk of developing depressive symptoms. Also, community development programs specifically targeting areas of economic disadvantage to promote neighborhood connectedness may impact positively on levels of well-being among parents. However, these ultimately raise more questions for future explorations: How can we effectively promote neighborhood connectedness for disadvantaged families? What does it mean for them? How comprehensive must their involvement be to strengthen belonging?

While the panel data used in this study are particularly strong for researching this topic because the LSAC has a nationally representative sample of Australian children and their families, there are certain limitations to this study. The present study was based on 1204 parents on welfare. Findings are relevant to this population, not necessarily to the Australian population at large. Care must also be taken in interpreting the results as they do not imply any causal relationships of depression with risk and protective factors, rather they only indicate predictive relationships over two years (2004 and 2006). As further waves of data become available, future research can disentangle causal relationships among depression, risk and protective factors.

In conclusion, this study complements and extends existing literature on depression, particularly by highlighting the key role that support service accessibility plays in alleviating depression among one of the most vulnerable population groups-parents with young children who are receiving welfare. The findings have important implications for inculcating resilience in families on welfare, in particular, through driving an institutional change that is responsive to ongoing and emergent needs at times of adversity (Blount, 2013). Given that three-quarters of all lifetime cases of mental illness begin by age 24 (Kessler et al., 2005) and can result in significant burden within our community if left untreated (Australian Institute of Health and Welfare, 2006; Hilton et al., 2007), early screening must be advocated as the most appropriate way to protect vulnerable families from potential undesirable long-term outcomes of depression. Investing in early diagnosis and intervention for depression with targeted and adequate support for one generation will surely promote healthy developmental outcomes for the next.

\section{References}

Aiken, L. S., \& West, S. G. (1991). Multiple Regression: Testing and Interpreting Interactions. Newbury Park: Sage.

Australian Bureau of Statistics (2007). National Survey of Mental Health and Wellbeing: 
Summary of Results. Canberra: ABS.

Australian Institute of Health and Welfare (2006). Chronic Diseases and Associated Risk Factors in Australia, Canberra: AIHW.

http://www.aihw.gov.au/publication-detail/?id=6442467914

Ayres, I., \& Braithwaite, J. (1992). Responsive Regulation: Transcending the Deregulation Debate. Oxford: Oxford University Press.

Bandura, A. (1977). Self-Efficacy: Toward a Unifying Theory of Behavioral Change. Psychological Review, 84, 191-215. https://doi.org/10.1037/0033-295X.84.2.191

Baxter, J., Qu, L., Weston, R., Moloney, L., \& Hayes, A. (2012). Experiences and Effects of Life Events: Evidence from Two Australian Longitudinal Studies. Family Matters Issue, 90, 6-18.

Beck, A. T. (1967). Depression: Clinical, Experimental, and Theoretical Aspects. New York: Harper \& Row.

Blount, A. (2013). Getting Mental Health Care Where It Is Needed. Families, Systems, \& Health, 31, 117-118. https://doi.org/10.1037/a0032496

Davidson, T., \& Singelmann, J. (2010). Determinants of Depressive Symptoms among Women on Public Assistance. Journal of Health Disparities Research and Practice, 4, 16-34.

De Silva, M., McKenzie, K., Harpham, T., \& Huttly, S. (2005). Social Capital and Mental Illness: A Systematic Review. Journal of Epidemiology Community Health, 59, 619-627.

Department of Health and Aged Care (2000). Promotion, Prevention and Early Intervention for Mental Health: A Monograph. Canberra, Mental Health and Special Programs Branch, Commonwealth Department of Health and Aged Care.

Eaton, W. W., Martins, S. S., Nestadt, G., Bienvenu, O. J., Clarke, D., \& Alexandre, P. (2008). The burden of Mental Disorders. Epidemiologic Reviews, 30, 1-14. https://doi.org/10.1093/epirev/mxn011

Edwards, B., \& Maguire, B. (2012). Parental Mental Health. In B. Maguire, \& B. Edwards (Eds.), The Longitudinal Study of Australian Children Annual Statistical Report 2011 (pp. 7-17). Melbourne: Australian Institute of Family Studies.

Fletcher, R., Feeman, E., Garfield, C., \& Vimpani, G. (2011). The Effects of Early Paternal Depression on Children's Development. Medical Journal of Australia, 195, 685-689. https://doi.org/10.5694/mjal1.10192

Gallo, W. T., Bradley, E. H., Siegel, M., \& Kasl, S. V. (2000). Health Effects of Involuntary Job Loss among Older Workers: Findings from the Health and Retirement Survey. Journals of Gerontology Series B: Psychological Sciences and Social Sciences, 55, S131-S140.

Gibb, B. E., Butler, A. C., \& Beck, J. S. (2003). Childhood Abuse, Depression, and Anxiety in Adult Psychiatric Outpatients. Depression and Anxiety, 17, 226-228.

Gray, M., \& Smart, D. (2008). Growing Up in Australia: The Longitudinal Study of Australian Children is Now Walking and Talking. Family Matters, 79, 5-13.

Greenfield, E. A., \& Marks, N. F. (2010). Sense of Community as a Protective Factor against Long-Term Psychological Effects of Childhood Violence. Social Service Review, 84, 129-147.

Hammen, C, Kim, E., Eberhart, N., \& Brennan, P. A. (2009). Chronic and Acute Stress and the Prediction of Major Depression in Women. Depression and Anxiety, 26, 718-723. https://doi.org/10.1002/da.20571

Hankin, B. L., Fraley, R. C., Lahey, B. B., \& Waldman, I. (2005). Is Youth Depressive Dis- 
order Best Viewed as a Continuum or Discrete Category? A Taxometric Analysis of Childhood and Adolescent Depression in a Population-Based Sample. Journal of $A b$ normal Psychology, 114, 96-110. https://doi.org/10.1037/0021-843X.114.1.96

Hilton, M., Sheridan, J., Cleary, C. M., Morgan, A., \& Whiteford, H. A. (2007). The Concealed Burden of Mental Health. Australian and New Zealand Journal of Psychiatry, 41, A32.

Howarth, E., Johnson, J., Klerman, G. L., \& Weissman, M. (1992). Depressive Symptoms as Relative and Attributable Riskfactors for First-Onset Major Depression. Archives of General Psychiatry, 49, 817-823.

Institute of Health Economics (2008). Consensus Statement on Depression in Adults: How to Improve Prevention, Diagnosis and Treatment (Vol. 3). Edmonton (AB): AHS.

Kawachi, I., \& Berkman, L. (2000). Social Cohesion, Social Capital and Health. In L. Berkman, \& I. Kawachi (Eds.), Social Epidemiology. New York: Oxford University Press.

Kessler, R. C., Green, J. G., Gruber, M. J., Sampson, N. A., Bromet, E., Cuitan, M., Furukawa, T. A., Gureje, O., Hinkov, H., Hu, C. Y., Lara, C., Lee, S., Mneimneh, Z., Myer, L., Oakley-Browne, M., Posada-Villa, J., Sagar, R., Viana, M. C., \& Zaslavsky, A. M. (2010). Screening for Serious Mental Illness in the General Population with the K6 Screening Scale: Results from the WHO World Mental Health (WMH) Survey Initiative. International Journal of Methods in Psychiatric Research, 19, 4-22. https://doi.org/10.1002/mpr.310

Kessler, R. C., Berglund, P. B., Demler, O., Jin, R. J., Merikangas, K. R., \& Walters, E. E. (2005). Lifetime Prevalence and Age-of-Onset Distributions of DSM-IV Disorders in the National Co-Morbidity Survey Replication (NCSR). General Psychiatry, 62, 593-602. https://doi.org/10.1001/archpsyc.62.6.593

Kessler, R. C., Barker, P. R., Colpe, L. J., Epstein, J. F., Gfroerer, J. C., Hiripi, E., Howes, M. J., Normand, S. L. T., Manderscheid, R. W., Walters, E. E., \& Zaslavsky, A. M. (2003). Screening for Serious Mental Illness in the General Population. Archives of General Psychiatry, 60, 184-189. https://doi.org/10.1001/archpsyc.60.2.184

Kessler, R. C., McGonagle, K. A., Zhao, S., Nelson, C. B., Hughes, M., Eshleman, S., Wittchen, H. U., \& Kendler, K. S. (1994). Lifetime and 12-Month Prevalence of DSM-III-R Psychiatric Disorders in the United States: Results from the National Comorbidity Survey. Archives of General Psychiatry, 51, 8-19. https://doi.org/10.1001/archpsyc.1994.03950010008002

Klein, D. N., Kotov, R., \& Bufferd S. J. (2011). Personality and Depression: Explanatory Models and Review of the Evidence. Annual Review of Clinical Psychology, 7, 269-295. https://doi.org/10.1146/annurev-clinpsy-032210-104540

Leahy-Warren, P., McCarthy, G., \& Corcoran, P. (2012). First Time Mothers: Social Support, Maternal Parental Self-Efficacy and Postnatal Depression. Journal of Clinical Nursing, 21, 388-397. https://doi.org/10.1111/j.1365-2702.2011.03701.x

Mayberry, D., Reupert, A., Goodyear, M., \& Crase, L. (2009). Prevalence of Children Whose Parent Has a Mental Illness. Psychiatric Bulletin, 33, 22-26. https://doi.org/10.1192/pb.bp.107.018861

New South Wales Department Of Community Services (2008). A Literature Review-Parents with Mental Health Issues: Consequences for Children and Effectiveness of Interventions Designed to Assist Children and Their Families. http://www.community.nsw.gov.au/_data/assets/pdf_file/0004/321646/research_pare ntalmentalhealth.pdf, Accessed 10.02.2018.

Patten, S. B., Wang, J. L., Williams, J. V., Currie, S., Beck, C. A., Maxwell, C. J., \& Gue- 
baly, N. (2006). Descriptive Epidemiology of Major Depression in Canada. Canadian Journal of Psychiatry, 51, 84-90. https://doi.org/10.1177/070674370605100204

Reupert, A., Maybery, D., \& Kowalenko, N. (2012). Children Whose Parents Have a Mental Illness: Prevalence, Need and Treatment. Medical Journal of Australia, 1, 7-9.

Robinson, E., Rodgers, B., \& Butterworth, P. (2008). Family Relationships and Mental Illness: Impacts and Service Responses. Australian Family Relationships Clearinghouse, Issues No. 4. Melbourne: Australian Institute of Family Studies.

Robinson, E., Scott, D., Meredith, V., Nair, L., \& Higgins, D. (2012). Good and Innovative Practice in Service Delivery to Vulnerable and Disadvantaged Families and Children (CFCA Paper No. 9). Melbourne: Australian Institute of Family Studies.

Sampson, R. J., Raudenbush, S. W., \& Earls, F. (1997). Neighbourhoods and Violent Crime: A Multilevel Study of Collective Efficacy. Science, 277, 918-924.

https://doi.org/10.1126/science.277.5328.918

The National Alliance on Mental Illness (2009). Women and Depression FACT SHEET. http://www.networkofcare.org/library/womenanddepression.pdf, Accessed 10.02.2018.

World Federation for Mental Health (2012). Depression: A Global Crisis. http://www.who.int/mental_health/management/depression/wfmh_paper_depression wmhd_2012.pdf, Accessed 10.02.2018. 